\title{
Enzymologic Studies and Therapy of Leigh's Disease Associated with Pyruvate Decarboxylase Deficiency
}

\author{
KENJI TOSHIMA, YASUHIRO KURODA, ${ }^{(44)}$ TOSHIAKI HASHIMOTO, MICHINORI ITO, \\ TOSHIYUKI WATANABE, MASUHIDE MIYAO, AND KUNIO II \\ Department of Pediatrics and First Department of Pathology, School of Medicine, Tokushima University, \\ Tokushima, Japan
}

\begin{abstract}
Summary
An 11-month-old boy with muscle hypotonia and neurologic deteriorations had lactic acidosis, pyruvic acidemia and alaninemia due to deficiency of the pyruvate dehydrogenase complex in his platelets and of pyruvate decarboxylase in his muscle. When placed on a low carbohydrate-high fat diet for $\mathbf{6}$ months, his blood levels of lactate and pyruvate became nearly normal, but his cerebrospinal fluid levels of lactate and pyruvate remained high. Despite this dietary therapy, neurologic deterioration progressed slowly. He died of pneumonia after artificial respiration for $3 \mathrm{wk}$. At autopsy, extensive symmetric necrotic lesions were found in the brain including proliferation of capillaries and gliosis in the brain stem and diffuse demyelination in the white matter. These lesions were consistent with those observed in Leigh's disease. The activities of the pyruvate dehydrogenase complex and pyruvate decarboxylase in various tissues obtained at autopsy were less than $10 \%$ of control values; however, the activities of pyruvate carboxylase and $\alpha$-ketoglutarate decarboxylase were within the normal limits. This patient with Leigh's disease had an isolated deficiency of pyruvate decarboxylase in various tissues.
\end{abstract}

\section{Speculation}

Deficiency of pyruvate decarboxylase in brain may be one cause of clinical and pathologic features of Leigh's disease. The absence of pyruvate decarboxylase in the cerebellum, cerebrum, kidney, liver, muscle and platelets of the patient supports the hypothesis that there is only one form of pyruvate decarboxylase in humans.

Subacute necrotizing encephalomyelopathy first described by Leigh (Leigh's disease) (26) is a degenerative disease of the central nervous system causing muscle hypotonia and mental and developmental deteriorations. It is generally inherited as an autosomal recessive disorder (30). Abnormal chemical findings in this disease include lactic acidosis, pyruvic acidemia, and elevation of the blood alanine level (41).

The pyruvate dehydrogenase complex contains three catalytic and two regulatory enzymes $(24,27)$. The three catalytic components are pyruvate dehydrogenase $\left(E_{1}\right)$, commonly referred to as pyruvate decarboxylase, (EC1.2.4.1), dihydrolipoyl transacetylase $\left(E_{2}\right)(E C 2.3 .1 .12)$, and dihydrolipoly dehydrogenase $\left(E_{3}\right)$ (EC 1.6.4.3.), which act sequentially in that order. The two regulatory enzymes are pyruvate dehydrogenase kinase (EC2.7.1.99), which catalyzes the Mg-ATP-dependent phosphorylation of pyruvate decarboxylase with concomitant inactivation, and pyruvate dehydrogenase phosphate phosphatase (EC3.1.3.43), which dephosphorylates pyruvate dehydrogenase phosphate with concomitant activation of the enzyme. Deficiencies of four different enzymes in the pyruvate dehydrogenase complex have been reported (3.9.36.37).
A number of biochemical abnormalities have been reported in Leigh's disease. Abnormalities of thiamine triphosphate metabolism $(10,11,33)$, transketolase (E.C.2.2.1.1.) $(29,35)$, pyruvate carboxylase (E.C.6.4.1.1.) (18, 21, 39), pyruvate decarboxylase (6, $15)$ and activation of the pyruvate dehydrogenase complex (13) have also been demonstrated to be associated with this disease. Pyruvate decarboxylase deficiency has been shown only in cultured skin fibroblasts from three patients with Leigh's disease. The variety of reported biochemical abnormalities in Leigh's disease suggests that this syndrome may result from various and as yet unknown biochemical disorders that produce similar clinical abnormalities; however, Leigh's disease can only be diagnosed definitely by finding a characteristic pattern of brain lesions at autopsy (34).

Recently, we encountered a patient with lactic acidosis who had muscle hypotonia, mental and developmental retardation and seizures. The activity of the pyruvate dehydrogenase complex in his platelets and a muscle biopsy specimen were markedly reduced. A diagnosis of Leigh's disease was established from autopsy findings.

This paper reports this case, its attempted therapy, and a description of the neurologic changes of the brain and the activities of pyruvate dehydrogenase and $\alpha$-ketoglutarate dehydrogenase complexes and pyruvate carboxylase in various tissues taken at autopsy.

\section{MATERIALS AND METHODS}

Amino acids were determined with a Hitachi 835 amino acid analyzer. Lactate, pyruvate, and $\alpha$-ketoglutarate were measured by enzymatic spectrophotometric methods $(19,31,32)$. Protein was measured using bovine serum albumin as a standard (28). The activities of the pyruvate dehydrogenase complex and $\alpha$ ketoglutarate dehydrogenase complex were measured by isotopic assay with $1-\left[{ }^{14} \mathrm{C}\right]$-pyruvate and $1-\left[{ }^{14} \mathrm{C}\right]-\alpha$-ketoglutarate, respectively, as substrates (7). The activities of pyruvate decarboxylase and $\alpha$-ketoglutarate decarboxylase (E.C.1.2.4.2.) were measured by ferricyanide linked assay $(5,25)$. The activity of pyruvate carboxylase was measured by an isotopic assay (1). The rate of activation of the pyruvate dehydrogenase complex in plateletes was determined by the method of Robinson and Sherwood (36). Tissues for assay were obtained by biopsy or autopsy within $3 \mathrm{~h}$ after death and after informed consent had been obtained. Autopsy tissues were thinly sliced and stored at $-80^{\circ} \mathrm{C}$ until used for determinations. All determinations were done within 4 months of obtaining the tissues. No decrease in enzyme activities was observed in repeated tests during the period of storage.

For low carbohydrate-high fat dietary therapy, Ketomeal (Wakodo, Tokyo), which contains $70 \%$ fat, $18 \%$ protein, $6.0 \%$ carbohydrate, vitamins and minerals, was used.

Case report. An 11-month-old boy had muscle hypotonia, men- 
tal and developmental retardation and seizures. His parents marriage was not consanguinal. He was the first child, delivered at term by cesarean section, and weighed $3200 \mathrm{~g}$ at birth. His muscles were flaccid and from birth he showed little spontaneous activity. Development was slow and he was unable to sit even at 11 months old. When grand mal seizures appeared, he was admitted to this hospital at 11 months old for detailed examinations of his muscle hypotonia, mental and developmental retardation and seizures. His extremities were hypotonic and his deep tendon reflexes were weak. There was no evidence of muscle atrophy or hypertrophy. His Tsumori-Inage's developmental quotient was 50 (normal 100). Results of other physical examinations were normal.

$\mathrm{He}$ was found to have lactic acidosis. Analysis of the arterial blood gave the following values; $\mathrm{pH}, 7.31 ; \mathrm{PCO}_{2}, 33.1 \mathrm{mmHg}$; standard bicarbonate, $18.8 \mathrm{mEq} / 1$; and base excess, $-5.2 \mathrm{mEq} / 1$. Oxygen saturation was normal. The concentration of lactate in the blood was 3.3-6.2 mM (normal 0.9-1.8 mM). The concentration of pyruvate ranged from $0.16-0.40 \mathrm{mM}$ (normal $0.05-0.12 \mathrm{mM}$ ). The concentration of $\alpha$-ketoglutarate was $0.01 \mathrm{mM}$ (normal $0.005-0.01 \mathrm{mM}$ ). The urine was found to contain a large amount of alanine: excretion of alanine was $3.1 \mu \mathrm{moles} / \mathrm{mg}$ creatinine (normal 0.4-1.4 $\mu$ moles $/ \mathrm{mg}$ creatinine). The plasma alanine level was $1.36 \mathrm{mM}$ (normal $0.13-0.34 \mathrm{mM}$ ) and the proline level was $0.36 \mathrm{mM}$ (normal $0.13-0.25 \mathrm{mM}$ ). The branched chain amino acid levels were not elevated. In a glucose-pyruvate test (14), $1.75 \mathrm{~g}$ of glucose per $\mathrm{kg}$ body weight dissolved in water was given orally after overnight fasting. His blood lactate and pyruvate levels increased abnormally after the oral glucose load (Fig. 1). His serum aspartate aminotransferase level was slightly elevated; however, normal values were obtained in tests for glutamic pyruvic transaminase, lactic dehydrogenase, creatine phosphokinase, aldolase, electrolytes, calcium, phosphorus, urea nitrogen, creatine, uric acid, cholesterol, triglyceride, thyroxine, glucose and ammo-
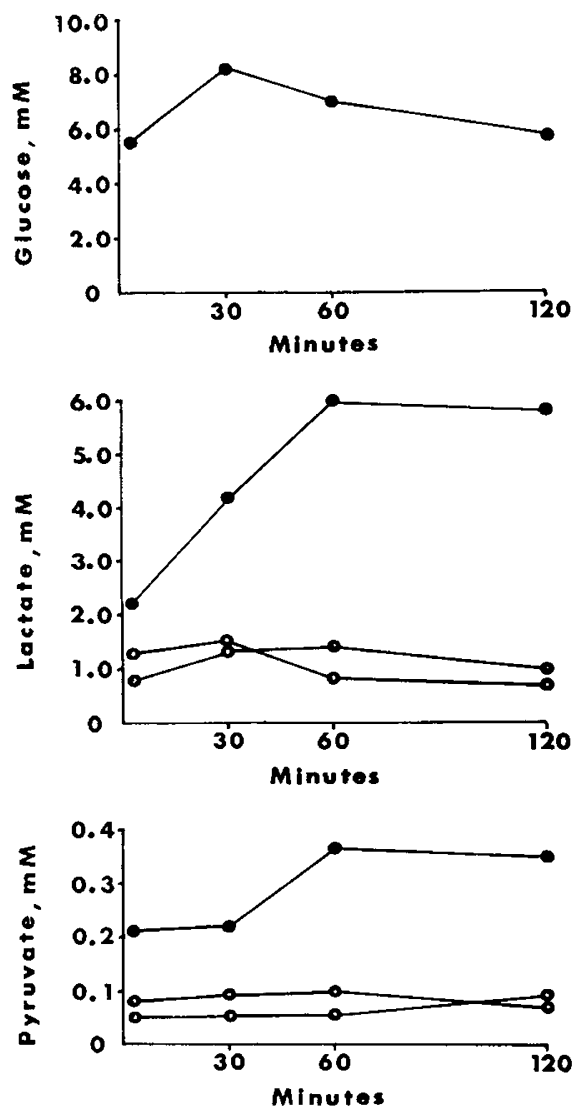

Fig. 1. Glucose, lactate and pyruvate values in blood during the glucose-pyruvate test described in the text. Closed circles and open circles represent values for the patient and controls, respectively. All control subjects gave normal glucose tolerance curves.
Table 1. Enzyme activities in platelets and biopsy specimens of muscle from the patient and controls ${ }^{1}$

\begin{tabular}{cccc}
\hline $\begin{array}{c}\text { Pyruvate dehy- } \\
\text { drogenase com- } \\
\text { plex }\end{array}$ & $\begin{array}{c}\text { Pyruvate } \\
\text { decarbox- } \\
\text { ylase }\end{array}$ & $\begin{array}{c}\alpha \text {-Ketoglutarate } \\
\text { dehydrogenase } \\
\text { complex }\end{array}$ & $\begin{array}{c}\alpha \text {-Keto- } \\
\text { glutarate } \\
\text { decarbox- } \\
\text { ylase }\end{array}$ \\
\hline \multicolumn{4}{c}{ (pmoles/min/mg protein) } \\
\hline
\end{tabular}

Platelets

$\begin{array}{lll}\text { Patients } & 13.6 \pm 2.6^{2}(3)^{3} & \text { Platelets } \\ \text { Controls } & 49.8 \pm 10.6 & 207.3 \pm 31.3(3) \\ (9)^{4} & & 200.4 \pm 55.3\end{array}$

$(9)^{4}$

$\begin{array}{lcccc}\text { Patient } & 13.6 & \text { Muscle } & 230.7 & 143.7 \\ \text { Control 1 } & 4.6 & 80.7 & 171.3 & 305.7 \\ \text { Control 2 }^{6} & 36.6 & 54.6 & 165.8 & 195.6\end{array}$

'Enzyme activities were determined in duplicate on fresh specimens.

${ }^{2}$ Mean \pm S.D.

${ }^{3}$ Number of assays.

${ }^{4}$ Number of normal subjects.

5 Control 1, 15-year-old boy with osteosarcoma.

${ }^{6}$ Control 2, 48-year-old woman with chronic rheumatoid arthritis.

nia. Results of routine cerebrospinal fluid examinations were normal. The motor nerve conduction velocity was $39.5 \mathrm{~m} / \mathrm{sec}$ in the right median nerve, which was lower than normal. A spike and wave complex was seen on electroencephalography of the left central area. Computed tomography revealed slight cortical atrophy with dilatation of the ventricles.

A muscle biopsy specimen was taken from the quadriceps at the age of 17 months. The muscle fibers, $15-25 \mu \mathrm{m}$ in diameter, showed no necrosis, regeneration, central nuclei or inflammatory changes, but type I fibers contained numerous lipid droplets, suggesting disturbance of lipid metabolism in the tissue. No "ragged red" fibers were seen. Muscle fibers stained for myofibrillar ATPase after preincubation at $\mathrm{pH} 9.4,4.6$, and 4.2 (8) revealed fiber-type grouping and an excess of type II $\mathrm{C}$ fibers. Electron microscopy also revealed an excess of lipid droplets, which were about $1 \mu \mathrm{m}$ in diameter and were adjacent to mitochondria. Neither enlarged mitochondria nor mitochondria containing crystalline-inclusions were seen.

As shown in Table 1, the activity of the pyruvate dehydrogenase complex in platelet-enriched preparations from the patient's blood was lower than the value of controls, whereas the activity of the $\alpha$-ketoglutarate dehydrogenase complex was normal. The activities of the pyruvate dehydrogenase complex and pyruvate decarboxylase in a biopsy specimen of his muscle were lower than those of 2 controls, whereas the activities of the $\alpha$-ketoglutarate dehydrogenase complex and $\alpha$-ketoglutarate decarboxylase were normal. As shown in table 2, preincubation of platelet homogenate for 3 min with $0.2 \mathrm{mM}$ ATP resulted in marked reduction of pyruvate dehydrogenase complex activity in both the patient and the controls. Addition of $2 \mathrm{mM} \mathrm{CaCl}$ to the inactivated enzyme resulted in rapid restoration of the activity in both the patient and the controls.

Results of therapy. After administration of phenobarbital (3 mg/ $\mathrm{kg}$ body weight/day) and sodium dipropyonylacetate $(30 \mathrm{mg} / \mathrm{kg}$ body weight/day), grand mal seizures disappeared, presumably in response to these drugs.

As shown in Figure 2, therapy was attempted by intramuscular injection of vitamin $B_{1}$ ( $10 \mathrm{mg} / \mathrm{kg}$ body weight/day) and administration of a low carbohydrate-high fat diet. After vitamin $\mathbf{B}_{1}$ therapy for $3 \mathrm{wk}$, no biochemical or clinical improvement was observed. Therapy with a low carbohydrate-high fat diet in the form of Ketomeal (approximately $130 \mathrm{Cal} / \mathrm{kg}$ body weight/day, $63 \%$ fat, $24 \%$ carbohydrate and $13 \%$ protein) was attempted for a period of 6 months. The levels of lactate and pyruvate in the blood and cerebrospinal fluid were measured simultaneously at 4 different times during this therapy. The lactate and pyruvate levels 
Table 2. Pyruvate dehydrogenase complex activity in platelets of the patients and controls ${ }^{1}$

Pyruvate dehydrogenase complex activity (pmoles/ $\mathrm{min} / \mathrm{mg}$ protein)

(a)

\begin{tabular}{cccc} 
Preincubation & No additions & ATP & ATP $+\mathrm{Ca}^{++}$ \\
\hline Control 1 & $48.1(100)$ & $28.2(58.6)$ & $37.4(77.8)$ \\
Control 2 & $56.1(100)$ & $31.8(56.7)$ & $44.5(79.3)$ \\
Patient & $13.0(100)$ & $7.3(56.2)$ & $12.1(93.1)$ \\
\hline
\end{tabular}

'Pyruvate dehydrogenase complex activity was determined in homogenates of platelets after the following preincubations: (a) no addition, (b) plus $0.2 \mathrm{mM}$ ATP for $3 \mathrm{~min}$, and (c) plus $0.2 \mathrm{mM}$ ATP for $3 \mathrm{~min}$ followed by $2 \mathrm{mM} \mathrm{Ca}^{++}$for $3 \mathrm{~min}$. Numbers in parenthesis show $\%$ activities of the pyruvate dehydrogenase complex.

in his blood were reduced to nearly normal (lactate, $1.6-2.4 \mathrm{mM}$ and pyruvate $0.13-0.23 \mathrm{mM}$ ), whereas those in his cerebrospinal fluid remained high (lactate, 4.0-4.3 mM, normal, 1.0-1.7 mM; pyruvate, $0.33-0.40 \mathrm{mM}$, normal, $0.07-0.11 \mathrm{mM}$ ). Urinary ketones were found by the commercial Acetest (Ames) to be elevated quantatively. No hypoglycemia or ketoacidosis was observed. Analysis of the arterial blood gave the following values during this therapy: $\mathrm{pH}, 7.40-7.44$; standard bicarbonate, $17.0-25.0 \mathrm{mEq} /$ 1 ; and base excess, -3.0 to $+1.0 \mathrm{mEq} / 1$. Weight gain was normal. Muscle weakness was improved. As a result he became able to sit, turn over, hold his head up and pick up toys; however, truncal ataxia became obvious, and optic nerve atrophy appeared after 4 months of this therapy. The developmental quotient, estimated by the Tsumori-Inage's method, fell to 37. At the age of 25 months, pulmonary aspiration developed abruptly following a minor infection and he died of pneumonia after artificial respiration for 3 wk.

Results of histopathologic examinations at autopsy. Grossly, the brain was soft, edematous and slightly swollen, weighing $840 \mathrm{~g}$. The leptomeninx was turbid. The cingulate, transtentorial and tonsillar herniations, which are frequently seen in the "respirator brain," were not observed and no vascular anomaly was noted.

Microscopically, the first striking finding was coagulation necrosis of the parenchyme and the stroma with marked proliferation of capillaries and gliosis. The lesions were symmetrical, sharply demarcated, and most marked in the globus pallidus, caudate nucleus, thalamus and hypothalamus in the diencephalon, the tegmentum (Fig. 3,4) and substantia nigra in the midbrain, the tegmentum and pedunculus cerebellaris medius in the pons, the formatio reticularis of the medullar oblongata and the posterior horn of the cervical spinal cord. Some lesions had foci of cystic softening. Similar, less marked lesions without cystic lesions were observed in the putamen and cerebral cortex and cerebellar medulla (Fig. 5). The nerve cells were degenerated to various extents (pyknosis, karyorhexis, increased eosinophilia) in proportion to the degree of necrosis. Scattered nerve cells were lost in the foci of cystic softening, but the nerve cells in the cerebral cortex and small granular cells in the cerebellar cortex (Fig. 5) were fairly well preserved in contrast to the severe involvement of the stroma.

The second outstanding finding was symmetrical demyelination of the nerve fibers. This was most remarkable in the tegmentum and formatio reticularis of the midbrain, pons and medulla oblongata, and the pedunculus cerebellaris medius, frequently associated with axonal change in foci of cystic softening. Less marked demyelination without axonal changes was observed in scattered regions in the cerebral medulla, internal capsule, cerebral peduncle, and optic nerve. The lesions of demyelination were also symmetrical. There was little involvement of mamillary bodies, except for very slight proliferation of capillaries.

The third unusual finding was nonspecific meningitis, consisting of moderate infiltration of lymphocytes and microgliosis, which was observed in the cerebrum and the cerebellum and which seemed to be related with massive necrotic lesions of the cerebral and cerebellar cortex. Similar, but less marked, lesions were also observed in the midbrain, pons, medulla oblongata, and optic nerve. The mamillary bodies were well preserved, whereas the substantia nigra was considerably involved, suggesting that the lesions were different from those in Wernicke's encephalopathy.

Displacement of cerebellar fragments and a foreign body reaction, which have frequently been observed in the "respirator brain," were not seen in the subdural and subarachnoidal space of the spinal cord. Furthermore, no focus of infarction was observed in the cerebrum, brainstem, diencephalon, cerebellum or spinal cord.

Results of biochemical studies on tissues obtained at autopsy. In the tissues examined, activity of the pyruvate dehydrogenase complex was highest in the cerebrum, and that of pyruvate carboxylase was highest in the liver (Table 3).
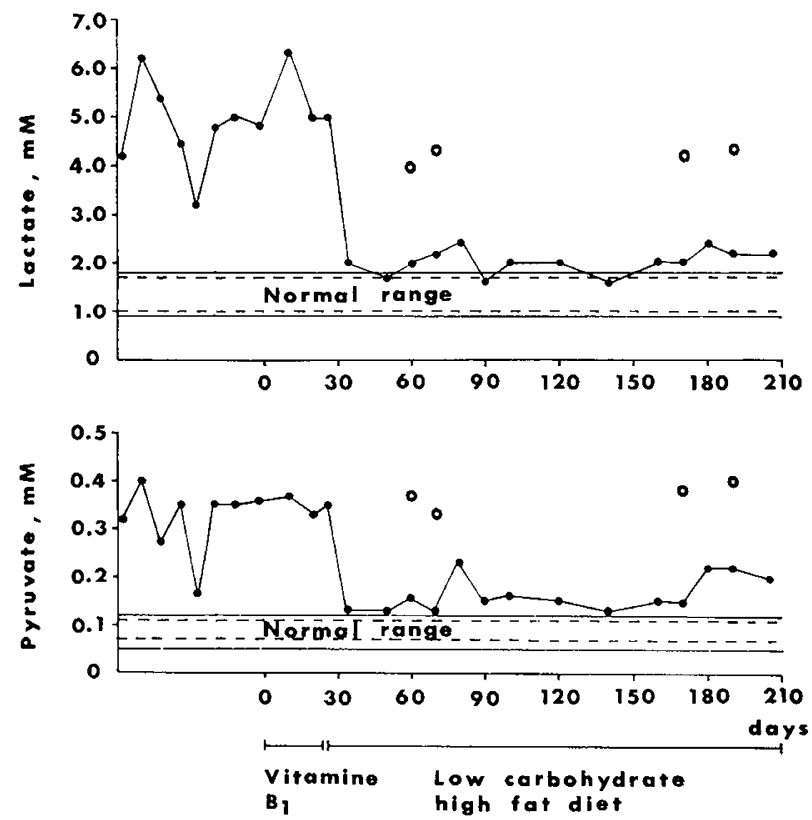

Fig. 2. Variations in blood and cerebrospinal fluid lactate and pyruvate in the patient over a 6-month period during the different forms of therapy described in the text. Closed circles indicate lactate or pyruvate values in the blood. Open circles indicate those in the cerebrospinal fluid. Dotted and continuous straight lines represent the normal ranges in the cerebrospinal fluid and blood, respectively.

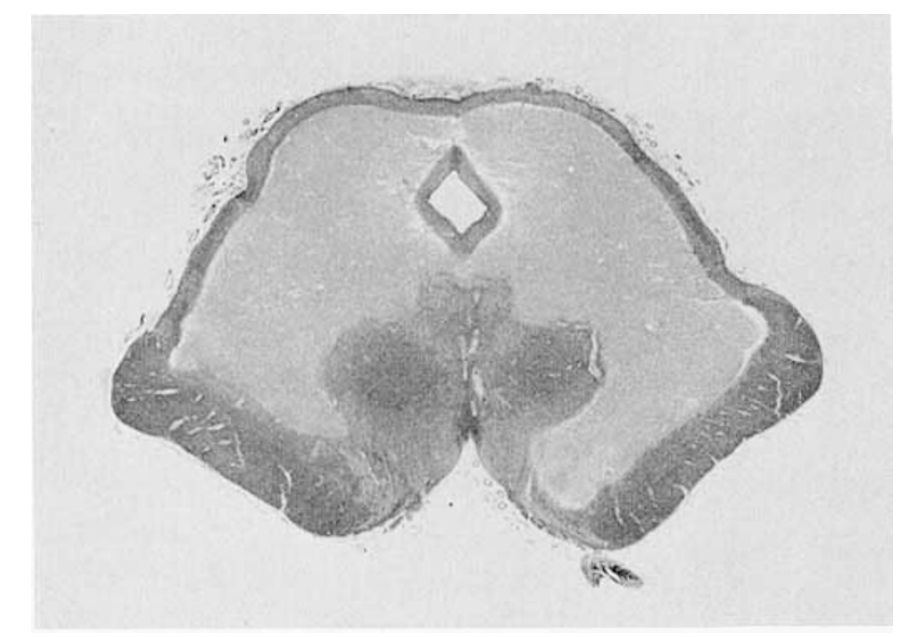

Fig. 3. Transverse section of the midbrain showing extensive symmetrical necrotic lesions not involving the crus cerebri, nucleus rubra, and nucleus oculomotorii of either side, or the marginal area $(\times 2.4$, Hematoxylin-Eosin stain) 
The activities of the pyruvate dehydrogenase complex and pyruvate decarboxylase were markedly reduced in the tissues tested, being less than $10 \%$ of the control activities in these individual tissues. The activities of the $\alpha$-ketoglutarate dehydrogenase complex, $\alpha$-ketoglutarate decarboxylase, and pyruvate carboxylase were essentially normal in all the tissues tested.

\section{DISCUSSION}

More than 100 cases of Leigh's disease have been reported, mostly in infants and young children. The concept of the disease has been expanded to include more chronic, often relapsing, forms in older children and even in adults.

We encountered an 11-month-old boy with lactic acidosis who had muscle hypotonia, mental and developmental retardation and seizures. Although Leigh's disease can only be diagnosed difinitely by finding a characteristic pattern of brain lesions at autopsy, this patient was suspected to have Leigh's disease based on clinical

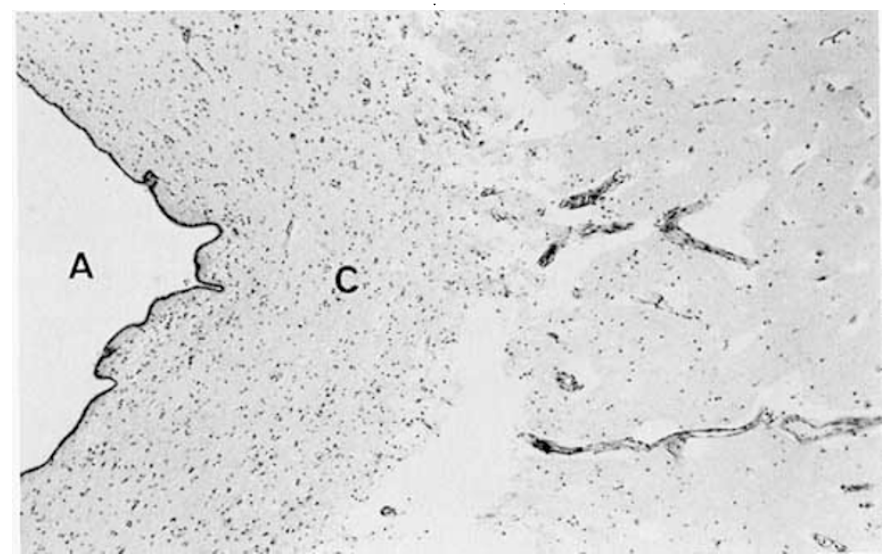

Fig. 4. Central area of the midbrain, showing a marked necrotic lesion (right half) with proliferation of capillaries and many cysts and a well preserved marginal zone $(\mathrm{C}$, left half) of the aqueductus cerebri $(\mathrm{A})(\times 60$, Hematoxylin-Eosin stain). and laboratory findings. The result of a glucose-pyruvate test also suggested that his glucose metabolism was blocked at the step of the pyruvate dehydrogenase complex. Enzyme assay showed that the activities of the pyruvate dehydrogenase complex in his platelets and a biopsy specimen of his muscle were reduced to about $30 \%$ of control values. Recently it has been reported that addition of dichloroacetate, which is an inhibitor of pyruvate dehydrogenase kinase, to the assay system of the pyruvate dehydrogenase complex increases the enzyme activity in normal tissue to about 10 times that found in previous assays (38). Therefore, with this activation procedure, the activities in platelets and muscle from this patient may in fact have been much lower than the values of $30 \%$ of contral values observed because the control values were actually higher.

At autopsy, most histologic findings on his brain were consistent with those observed in patients with Leigh's disease $(13,22,26$, 30). Cerebral involvement is uncommon, but has been described

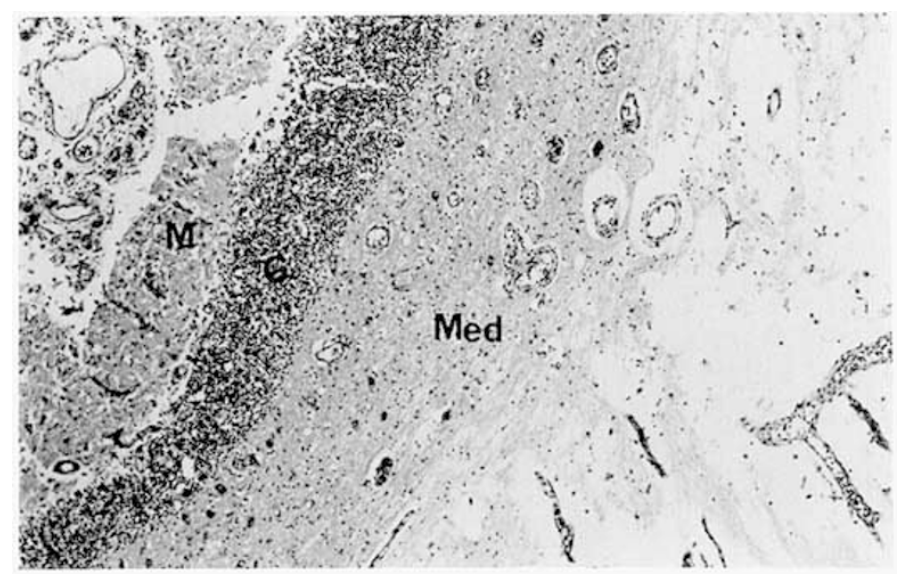

Fig. 5. Cerebellar cortex and medulla. Note the well preserved small nerve cells in the stratum granulosum of the cortex $(G)$ in contrast to the marked necrotic lesion with proliferation of capillaries and cysts in the stratum moleculare of the cortex $(\mathrm{M})$ and medulla (Med) $(\times 100$, Hematoxylin-Eosin stain).

Table 3. Enzyme activities in various autopsy tissues of the patient with Leigh's disease and controls ${ }^{1}$

\begin{tabular}{|c|c|c|c|c|c|}
\hline & $\begin{array}{c}\text { Pyruvate dehydrogenase } \\
\text { complex }\end{array}$ & Pyruvate decarboxylase & $\begin{array}{l}\alpha \text {-Ketoglutarate dehydro- } \\
\text { genase complex }\end{array}$ & $\begin{array}{l}\alpha \text {-Ketoglutarate decar- } \\
\text { boxylase }\end{array}$ & Pyruvate carboxylase \\
\hline & \multicolumn{4}{|c|}{ (pmoles/min/mg protein) } & (nmoles/min/mg protein) \\
\hline \multicolumn{6}{|c|}{ Cerebellum } \\
\hline Patient & N.D. ${ }^{2}$ & $0.6^{: 3}$ & 83.5 & 62.1 & 0.77 \\
\hline Control $\mathrm{I}^{4}$ & 245.0 & 65.5 & 200.5 & 112.2 & 0.24 \\
\hline Control $2^{5}$ & 194.2 & 56.7 & 281.7 & 123.3 & 0.11 \\
\hline \multicolumn{6}{|c|}{ Cerebrum } \\
\hline Patient & 1.3 & 3.2 & 109.2 & 62.8 & 0.50 \\
\hline Control 1 & 651.0 & 202.5 & 449.8 & 313.3 & 0.78 \\
\hline Control 2 & 562.2 & 198.7 & 248.6 & 172.4 & 0.34 \\
\hline Control $3^{i}$ & 427.3 & 207.5 & 483.1 & 315.3 & 0.39 \\
\hline \multicolumn{6}{|c|}{ Kidney } \\
\hline Patient & 40.0 & 12.0 & 949.2 & 1457.7 & 0.26 \\
\hline Control 1 & 434.4 & 154.8 & 1771.1 & 1711.8 & 1.80 \\
\hline Control $4^{i}$ & 246.8 & 74.7 & 784.8 & 1365.1 & 0.23 \\
\hline \multicolumn{6}{|c|}{ Liver } \\
\hline Patient & N.D. & 3.9 & 313.9 & 117.8 & 8.10 \\
\hline Control l & 123.4 & 48.1 & 456.3 & 164.4 & 18.85 \\
\hline Control 2 & 116.2 & 35.0 & 441.5 & 183.8 & 12.77 \\
\hline Control 3 & 104.8 & 38.5 & 380.5 & 153.8 & 15.55 \\
\hline Control 4 & 130.2 & 35.3 & 466.7 & 238.9 & 20.73 \\
\hline
\end{tabular}

'Tissues were obtained within $3 \mathrm{~h}$ after death and immediately frozen at $-80^{\circ} \mathrm{C}$.

2 N.D. indicates not detectable.

"Values are means of duplicate determinations.

${ }^{4}$ Control 1, 4-year-old boy with Menkes kinky hair disease.

s Control 2, adult with myocardial infarction.

"Control 3, adult with brain hemorrhage.

' Control 4, 7-month-old girl with malignant teratoma. 
in a few cases of Leigh's disease (30). The marked involvement of the cerebral and cerebellar cortices and meningitis in the patient may be hypoxic changes due to long-term artificial respiration, which is known as "respirator brain" (40). Adult and newborn patients with Leigh's disease in which a respirator was used for 4 and $2 \mathrm{wk}$, respectively, have been reported. In these patients, preservation of many neurons were observed in areas of tissue destruction, which contrasted with hypoxic changes $(16,17)$. The nerve cells in the cerebral cortex and the small nerve cells in the cerebellar cortex, which were most sensitive to hypoxia, were also well preserved in our patient in spite of extensive and severe involvement of the brain tissue. Furthermore, in contrast to changes in "respirator brain," the white matters in the brain stem and cerebellum showed specifically localized symmetrical demyelination. Therefore, the lesions in the brain of our patient represented essential changes of Leigh's disease, though hypoxic changes may have been superimposed on some of the lesions.

A number of biochemical abnormalities have been reported in Leigh's disease, but a defect of the pyruvate dehydrogenase complex has been shown in only a few patients with this disease. Reduced activity of pyruvate decarboxylase in cultured skin fibroblasts from cases of Leigh's disease has been described in brief reports and a defect in the activation mechanism of the pyruvate dehydrogenase complex has been observed in the liver and brain, but not in fibroblasts, from a patient with Leigh's disease $(6,13$, 15). The activity of pyruvate decarboxylase was markedly reduced in various tissues obtained within $3 \mathrm{~h}$ after death from our patient. The activity of the pyruvate dehydrogenase complex in platelets preincubated with ATP was reduced in the patient owing to inactivation of pyruvate decarboxylase by pyruvate dehydrogenase kinase. Addition of $\mathrm{CaCl}_{2}$ to the inactivated enzyme caused prompt increase to about $90 \%$ of the original activity. These findings suggest that there was no defect in the activation mechanism of the pyruvate dehydrogenase complex in our patient.

A patient who was suspected to have a defect of the $E_{2}$ component of pyruvate dehydrogenase complex has been reported. The activity of the pyruvate dehydrogenase complex in fibroblasts from this patient was significantly less than that in fibroblasts of control subjects. The activities of pyruvate decarboxylase $\left(\mathrm{E}_{1}\right)$ and the $\alpha$-ketoglutarate dehydrogenase complex were within normal limits (9). The activities of the pyruvate dehydrogenase and $\alpha$ ketoglutarate dehydrogenase complexes were both reduced in tissues from a patient with a defect of the $E_{3}$ component of pyruvate dehydrogenase complex, which was the same protein in the two complexes (37); however, the activities of the pyruvate decarboxylase and the pyruvate dehydrogenase complex were both markedly reduced and the activity of the $\alpha$-ketoglutarate dehydrogenase complex was normal in various tissues from our patient. From these findings, it is reasonable to conclude that our patient had no defect of the $\mathrm{E}_{2}$ or $\mathrm{E}_{3}$ component of the pyruvate dehydrogenase complex, but had an isolated deficiency of the pyruvate decarboxylase although we did not measure the activities of the $E_{2}$ and $E_{3}$ components of the pyruvate dehydrogenase complex directly.

It is unknown whether there are qualitatively different forms of the pyruvate dehydrogenase complex in different tissues and cell types, but extensive studies on purified pyruvate dehydrogenase complex from several animals tissues have not provided any evidence of isozymes $(2,4)$. We found reduced activity of the pyruvate dehydrogenase complex in all examined tissues from our patient with Leigh's disease examined; namely, the cerebellum, cerebrum, kidney, liver, muscle and platelets. These findings support the hypothesis that there are no isoenzymes of the pyruvate dehydrogenase complex, including pyruvate decarboxylase, in humans, and that examination of easily obtainable platelets for the pyruvate dehydrogenase complex is a valid method for diagnosing this disease during life.

The pyruvate dehydrogenase complex catalyzes the oxidation of pyruvate to acetyl-CoA and is the main enzyme system responsible for entry of glucose into the tricarboxylic acid cycle. Acetyl-
CoA can also be formed directly by the oxidation of fatty acids, and enter the tricarboxylic acid cycle distal to the step catalyzed by the pyruvate dehydrogenase complex. Brain cannot oxidize fatty acids directly, but can utilize ketone bodies formed by the oxidation of fatty acids in the liver, when their concentration in the blood is in a millimolar range (20). For this reason, it was suggested that therapy with a low carbohydrate-high fat diet might be effective in patients with pyruvate dehydrogenase complex deficiency $(9,14)$. This suggestion encouraged us to test a low carbohydrate-high fat diet on our patient. His blood levels of lactate and pyruvate fell to nearly normal levels during this therapy; however, the levels in his cerebrospinal fluid remained high, and neurologic deterioration progressed slowly. These findings indicate that a low carbohydrate-high fat diet improved his abnormal pyruvate metabolism in the liver, but not in the brain. The pathways of pyruvate utilization are gluconeogenesis, oxidation and lipogenesis. The major pathway is gluconeogenesis in the liver, oxidation in the brain, and lipogenesis in adipose tissue (12). Metabolism in the brain depends on oxidation of pyruvate derived from blood glucose, when the glucose supply is adequate. The activities of the pyruvate dehydrogenase complex in specimens of liver and brain of the patient was less than $10 \%$ of the control activities, but the activity of pyruvate carboxylase in the liver was much higher than that in brain. Thus most of the pyruvate derived from glucose could not be converted to oxaloacetate in the brain of the patient with pyruvate decarboxylase deficiency, but it could be converted to oxaloacetate in the liver and enter the gluconeogenesis cycle. These different activities of pyruvate carboxylase in the brain and liver may explain the discrepancy between the effects of a low carbohydrate-high fat diet on the lactate levels of the cerebrospinal fluid and blood. A high lactate level in the cerebrospinal fluid reflects lactic acidosis in the brain, since there is a close correlation between the lactate concentration in the cerebrospinal fluid and that in brain tissue (23). Thus it is important to maintain the lactate level in a normal range not only in the blood but also in the cerebrospinal fluid in therapy of pyruvate dehydrogenase deficiency.

\section{REFERENCES AND NOTES}

I. Atkin, B. H., Bruist, N. R. M., Utter, M. F., Leiter, A. B., and Banker, B. Q. Pyruvate carboxylase deficiency and lactic acidosis in a retarded child without Leigh's disease. Pediatr. Res., 13: 109 (1979).

2. Barrera, C. R.. Namihira, G., Hamilton, L., Munk, P., Eley, M. H., Linn, T. C. and Reed, L. J.: $\alpha$-Keto acid dehydrogenase complexes. XVI. Studies on the subunit structure of the pyruvate dehydrogenase complexes from bovine kidney and heart. Arch. Biochem. Biophy.. 148: 343 (1972).

3. Blass, J. P.. Avigan, J., and Uhlendorf, W.: A defect in pyruvate decarboxylase in a child with an intermittent movement disorder. J. Clin. Invest., 49: 423 (1970).

4. Blass, J. P. and Lewis, C. A.: Kinetic properties of the partially purified pyruvate dehydrogenase complex of ox brain. Biochem. J., 131:31 (1973).

5. Blass, J. P. Kark, R. A. P., and Menon, N. K.: Low activities of pyruvate and oxoglutarate dehydrogenase complexes in five patients with Friendreich's ataxia. N. Engl. J. Med., 295: 62 (1976).

6. Blass, J. P. Cederbaum, S. D., and Dunn, H. G.: Biochemical abnormalities in Leigh's disease. Lancet, 1: 1237 (1976).

7. Blass, J. P., Cederbaum, S. D., and Kark, R. A. P.: Rapid diagnosis of pyruvate and ketoglutarate dehydrogenase deficiencies in platelet-enriched preparations from blood. Clin. Chim. Acta, 75: 21 (1977).

8. Brook, M. H. and Kaiser, K. K.: Muscle fiber types; how many and what kind? Arch. Neurol., 23: 369 (1970).

9. Cederbaum, S. D., Blass, J. P., Minkoff, N., Brown, W. J., Cotton, M. E., and Harris. S. H.: Sensitivity to carbohydrate in a patient with familial intermittent lactic acidosis and pyruvate dehydrogenase deficiency. Pediatr. Res., 10:713 (1976).

10. Cooper, J. R., Itokawa, Y., and Pincus, J. H.: Thiamine triphosphate deficiency in subacute necrotizing encephalomyelopathy. Science, 164: 72 (1969).

11. Cooper, J. R., Pincus, J. H.. Itokawa, Y., and Piros, K.: Experience with phosphoryl transferase inhibition in subacute necrotizing encephalomyelopathy. N. Engl. J. Med., 283: 793 (1970).

12. Denton, R. M. and Halestrap. A. P.: Pathways and regulation of pyruvate metabolism. In: D. Bruman, J. B. Holton and C. A. Pennock: Inherited disorders of carbohydrate metabolism. p. 209 (MTP Press, Lancaster, 1980).

13. DeVivo, D. C., Haymond, M. W., Obert, K. A., Nelson, J. S., and Pagliara, A. S.: Defective activation of the pyruvate dehydrogenase complex in subacute necrotizing encephalomyelopathy (Leigh`s Disease). Ann. Neurol., 6: 483 (1979). 
14. Falk, R. E., Cederbaum, S. D., Blass, J. P., Gibson, G. E.. Kark, R. A. P., and Carrel, R. E.: Ketonic diet in the management of pyruvate dehydrogenase deficiency. Pediatrics, 58: 713 (1976).

15. Farmer, T. W., Veath, L., Miller, A. L., O’Brien, J. S., and Rosenberg, R. M.: Pyruvate decarboxylase deficiency in a patient with subacute necrotizing encephalomyelopathy (Abstract). Neurology, 23: 429 (1973).

16. Feigin, I., and Budzilovich, G. N.: Further observations on subacute necrotizing encephalomyelopathy in adults. J. Neuropath. Exp. Neurol., 36: 128 (1977).

17. Feigin. I. and Kim. H. S.: Subacute necrotizing encephalomyelopathy in a neonatal infant. J. Neuropath. Exp. Neurol., 36: 364 (1977).

18. Grover, W. D., Auerbach, V. H., and Pate, M. S.: Biochemical studies and therapy in subacute necrotizing encephalomyelopathy (Leigh's disease). J. Pediatr., 81: 39 (1972).

19. Gutman, I and Wahlfeld, A. W: $\mathrm{L}-(+)$-lactate: determination with lactate dehydrogenase and NAD. In: Hans U. Bergmeyer, Ed.: Methods of enzymatic analysis. pp. 1464-1468 (Academic Press, New York, 1974).

20. Hawkins, R. A., Williamson, D. H., and Krebs, H. A.: Ketone-body utilization by adult and suckling rat brain in vivo. Biochem. J., 122: 13 (1971).

21. Homes, F. A., Polman, H. A., and Reerink, J. D.: Leigh's encephalomyelopathy an inborn error of gluconeogenesis. Arch. Dis. Child.. 43: 423 (1968).

22. Kamoshita, S., Agilar, M. J., and Landing, B. H.: Infantile subacute necrotizing encephalomyelopathy. Am. J. Dis. Child., 116: 120 (1968).

23. Kazemi, H., Valenca, L. M., and Shanon, D. C.: Brain and cerebrospinal fluid lactate concentration in respiratory acidosis and alkalosis. Resp. Physiol., 6: 178 (1969)

24. Koike, M., Reed, L. J., and Carolle, W. G.: $\alpha$-Keto acid dehydrogenation complexes. IV. Resolution and reconstitution of the Escherichia coli pyruvate dehydrogenation complexes. J. Biol. Chem., 238: 30 (1963)

25. Kuroda, Y., Kline, J. J., Sweetman, L., Nyhan, W. L., and Groshong, T. D.: Abnormal pyruvate and $\alpha$-ketoglutarate dehydrogenase complexes in a patient with lactic acidosis. Pediatr. Res., 13: 928 (1979).

26. Leigh, D. J.: Subacute necrotizing encephalomyelopathy in an infant. J. Neurol. Neurosurg. Psychiatr., 14: 216 (1951).

27. Linn, T. C.. Pelly, J. W., Pettit, F. H., Hucho, F., Randall, D. D., and Reed, L. J.: $\alpha$-Keto acid dehydrogenase complexes. XV. Purification and properties of the component enzymes of the pyruvate dehydrogenase complexes from the bovine kidney and heart. Arch. Biochem. Biophy., 148: 327 (1972).

28. Lowry, O. H., Rosenbrough, N. J., Farr, A. L., and Randall, R. J.: Protein measurement with the Folin phenol reagent. J. Biol. Chem., 193: 265 (1951).

29. MacBurney, A., Leigh, D., and Mcllwain, H.: Erythrocyte transketolase activity in suspected cases of Leigh's disease, or subacute necrotizing encephalomye- lopathy. Arch. Dis. Child., 55: 789 (1980).

30. Montpetit, V. J. A.. Anderman. F., Carpenter, S., Fawcett, J. S., ZborowskaSluis, D., and Giberson, H. R.: Subacute necrotizing encephalomyelopathy; a review and a study of two families. Brain, 94: 1 (1971).

31. Narins, R. G. and Passoneau, J. V.: 2-Oxoglutarate; fluometric determination In: Hans U. Bergmeyer Ed.: Methods of enzymatic analysis. p. 1580-1584 (Academic Press, New York, 1974).

32. Passoneau, J. V. and Lowry, O. H.: Pyruvate: fluometric assay. In: Hans U. Bergmeyer, Ed.: Methods of enzymatic analysis. p. 1452-1456. (Academic Press, New York, 1974).

33. Pincus, J. H., Itokawa, Y., and Cooper, J. R.: Enzyme-inhibiting factor in subacute necrotizing encephalomyelopathy. Neurology, 19: 841 (1969).

34. Pincus. J. H.: Subacute necrotizing encephalomyelopathy (Leigh's disease); a consideration of clinical features and etiology. Child. Neurol., 14: 87 (1972).

35. Reed, M. A.: Leigh's disease: a family study. Lancet, 1: 1237 (1976).

36. Robinson, B. H. and Sherwood, W. G.: Pyruvate dehydrogenase phosphatase deficiency; a cause of congenital chronic lactic acidosis in infancy. Pediatr. Res., 9: 935 (1975).

37. Robinson, B. H., Taylor, J., and Sherwood, W. G.: Deficiency of dihydrolipoyl dehydrogenase (a component of the pyruvate and $\alpha$-ketoglutarate dehydrogenase complexes): a cause of congenital chronic lactic acidosis in infancy. Pediatr. Res., 11: 1198 (1977).

38. Sheu, K.F. R., Hu, C. W. C., and Utter, M. F.: Pyruvate dehydrogenase complex activity in normal and deficient fibroblasts. J. Clin. Invest., 67: 1463 (1981).

39. Tang, T. T., Good, T. A., Dyken, P. R., Johnson, S. D., McCreadie, S. R., Sy, S. . ., Lardy, H. A., and Rudolph, F. B.: Pathogenesis of Leigh's encephalomyelopathy. J. Pediatr.. 81: 189 (1972).

40. Walker, A. E., Diamond, E. L., and Mosely, J.: The neuropathological findings in irreversible coma; a critique of the "respirator brain." J. Neuropath. Exp. Neurol., 34: 295 (1975).

41. Worsley, H. E., Brookfield, R. W., and Elwood, J. S.: Lactic acidosis with necrotizing encephalopathy in two sibs. Arch. Dis. Child., 40: 492 (1965).

42. The authors wish to thank Drs. M. Koike, K. Kusaka, K. Hizawa and S Kamoshita for helpful suggestions and advice.

43. The authors obtained informed consent for this investigation from the parents of the patient.

44. Requests for reprints should be addressed to: Dr. Y. Kuroda, Department of Pediatrics. School of Medicine. Tokushima University, 2-Kuramoto-cho, Tokushima 770, Japan.

45. Received for publication June 17, 1981.

46. Accepted for publication February 4, 1982. 